\title{
Pattern of congenital eye anomalies in children: A study from rural tertiary care hospital
}

\author{
Rakhi Jain ${ }^{1}$, Vishal Pathania ${ }^{2}$, Nishtha Saini ${ }^{3}$ \\ ${ }^{1}$ Associate Professor, Department of Paediatrics, ${ }^{3}$ Professor, Department of Ophthalmology, SHKM, Government \\ Medical College, Nuh, ${ }^{2}$ Professor, Department of Otorhinolaryngology, World College of Medical Sciences and \\ Research, Jhajjar, Haryana, India
}

Background: Congenital eye anomalies are an important cause of childhood blindness. Worldwide, there are a lot of variations in the spectrum of congenital eye anomalies. The key to preventing childhood blindness is early detection and intervention of the congenital eye anomalies. Aims and Objectives: This study aims to describe the type and frequency of congenital eye anomalies in children. Materials and Methods: This cross-sectional study was done on children attending pediatric OPD and the newborn babies born in the hospital in the period of 1 year from June 2019 to May 2020. They were screened for any ocular abnormality and then detailed ocular examination was done by the ophthalmologist. The data were collected for demographic characteristics, clinical diagnosis, age of presentation of anomaly, laterality, involvement of one or both eye, and type of anomaly. Variables were expressed as proportions or percentages. Results: A total of 32,858 children were screened for ocular abnormalities. Out of these, $1571(0.047 \%)$ children had ocular abnormalities. Among them, $1011(64.35 \%)$ presented in the $1^{\text {st }}$ year of life, $381(24.25 \%)$ in the $2^{\text {nd }}$ year of life, and the remaining 179 (11.4\%) were diagnosed after 2 years of life. Among various anomalies, congenital nasolacrimal duct obstruction was the most common anomaly (65\%) followed by coloboma of iris and choroid (13.8\%). Congenital ectropion and anopthalmos were found in five and three children, respectively. Conclusion: The most common anomaly was congenital nasolacrimal duct blockage followed by coloboma of iris, choroid, and cataract. Early detection and intervention of the congenital eye anomalies is necessary to prevent blindness.

Key words: Childhood blindness; Congenital; Early diagnosis; Eye anomalies

\section{Access this article online}

Website:

http://nepjol.info/index.php/AJMS DOI: 10.3126/ajms.v13i2.40720

E-ISSN: 2091-0576

P-ISSN: 2467-9100

Copyright (c) 2022 Asian Journal of Medical Sciences

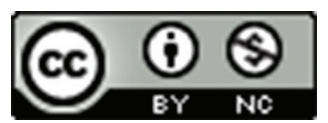

This work is licensed under a Creative Commons Attribution-NonCommercial 4.0 International License.

\section{INTRODUCTION}

To begin with, there are 36 million people in the world are blind. ${ }^{1}$ Congenital eye abnormalities are a leading cause of childhood blindness, ${ }^{2}$ accounting for approximately $60 \%$ of all cases. ${ }^{3}$ In the age category of $0-14$ years, 1.4 million children throughout the world are blind. ${ }^{4}$ Congenital abnormalities of the eyes are the leading cause of childhood blindness worldwide. In children, ocular abnormalities account for $15-20 \%$ of blindness and severe vision impairment. ${ }^{5}$ Early onset of blindness in a child results in a large number of blind years, which has a substantial socioeconomic impact. ${ }^{6-8}$
Any anomaly in the eye and surrounding tissue can occur on its own or as part of a multisystem miscreation syndrome. The cause of most of these abnormalities is unclear, but genetic and environmental factors both play a role. ${ }^{9-11}$ The specific genetic location of many eye abnormalities is known, but for many others, it is unknown. Ocular miscreations can be caused by both germline and somatic mutations.

Ocular congenital abnormalities include malformation, distortion, disruption, and dysplasia. Congenital cataract and glaucoma are the most prevalent diseases in poor 
countries, and they are frequently caused by preventable causes. ${ }^{12,13}$ Anophthalmos, microphthalmos, and coloboma are the most common congenital abnormalities in affluent nations, and are primarily due to unavoidable reasons. ${ }^{14}$ Congenital abnormalities are most commonly seen at birth, and in certain cases, even in pregnancy, however, the age of onset might vary. Maternal factors, in addition to hereditary ones, have a major influence. Maternal malnutrition, diseases such as rubella, CMV, toxoplasmosis, and varicella, as well as a history of drug use and alcohol consumption, all have a role.

In this area, the literacy rate is very low with poor health awareness and there are high chances of consanguinity. There is coexistence of maternal malnutrition and infections. All these contribute to high chances of congenital abnormality. Hence, this study was planned to find out the spectrum of congenital eye anomalies.

\section{Aims and objectives}

The study was conducted with the aim and objective to describe the type and frequency of congenital eye anomalies.

\section{MATERIALS AND METHODS}

This cross-sectional observational study was carried out at the Department of Pediatrics, SHKM, GMC, Nalhar, Nuh, Haryana, in coherence with the Department of Ophthalmology. Ethical approval was obtained from the Institutional Ethics Committee of our institute and informed consent was taken before performing all procedures. All the patients attending pediatric OPD and the newborn babies born in the hospital in the period of 1 year from June 2019 to May 2020 were included in the study. They were screened for any ocular abnormality. Exclusion criteria for the study were the cases of retinopathy of prematurity and retinoblastoma. The data were collected for demographic characteristics, clinical diagnosis, age of presentation of anomaly, laterality, involvement of one or both eye, type of anomaly, and any associated systemic complaints.

First and foremost, clinical examination was done by the pediatrician and all the children with suspected ocular abnormalities were referred to the ophthalmology department. The detailed ocular examination was done by the ophthalmologist which included broad light examination, slit-lamp examination, fundus examination, and IOP recording with applanation tonometer whenever possible. Vision examination was done in detail along with wet retinoscopy, auto-refractokeratometer, and refraction.

\section{Statistical analysis}

Quantitative variables, demographic variables, were expressed as a number and frequency, while qualitative variables were expressed as proportions or percentages.

\section{RESULTS}

The total pediatric OPD from June 2019 to May 2020 was 31,258 and total live births were 1600 . Hence, a total of 32,858 children were screened for ocular abnormalities. Out of these, $1571(0.047 \%)$ children had ocular abnormalities. The frequency of various congenital anomalies with sex wise distribution is depicted in Table1.

Hence, $0.047 \%$ of the children attending the hospital and born in the hospital were having ocular abnormalities. Out of these, 902 were male children which comprised $57.42 \%$ of the affected children. The remaining 669 were female children which comprised $42.58 \%$ of the affected children.

Out of 1571 children, 1011 (64.35\%) presented in the $1^{\text {st }}$ year of life. Three hundred and eighty-one $(24.25 \%)$ of these were diagnosed in the $2^{\text {nd }}$ year of life, the remaining $179(11.4 \%)$ were accidently diagnosed after 2 years of life. These $11.4 \%$ had visited hospital for other reasons and were incidentally diagnosed with ocular abnormalities. The most common eye anomaly was congenital NLD blockage (65\%) followed by coloboma of iris and choroid (13.8\%) depicted in Figures 1,2. Congenital ectropion and anopthalmos were found in five and three children, respectively. Congenital esotropia was detected in $23(1.46 \%)$ cases (Figure 3) and congenital ptosis was observed in $8(0.5 \%)$ children (Figure 4).

Many of these children were managed very well in our center and only few were referred to higher center for further management.

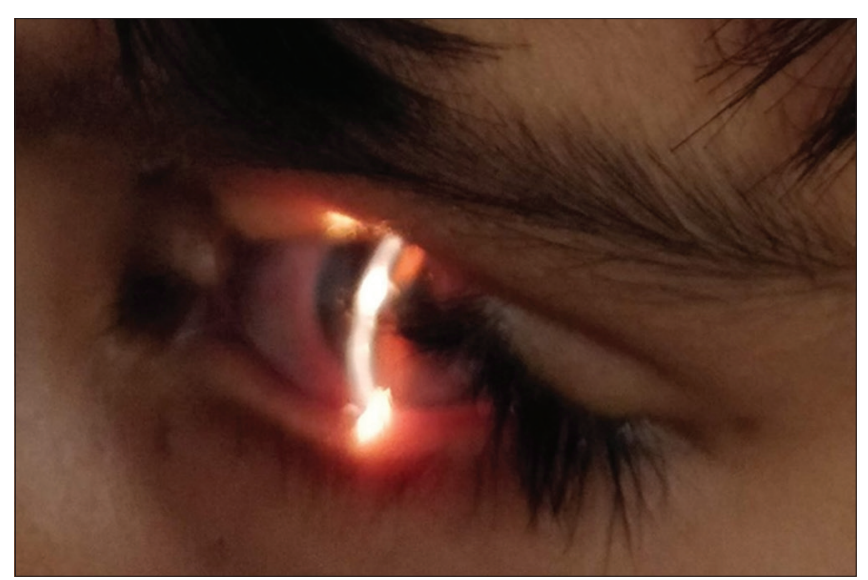

Figure 1: Lid coloboma 


\begin{tabular}{|c|c|c|c|c|}
\hline S. No. & Eye anomaly & $\begin{array}{l}\text { Total children, } \\
\text { no. }(\%)\end{array}$ & Male children & Female children \\
\hline 1. & Congenital NLD blockage & $1021(65 \%)$ & 578 & 443 \\
\hline 2. & Coloboma of iris and choroid & $218(13.8 \%)$ & 118 & 100 \\
\hline 3. & Congenital cataract & $167(10.6 \%)$ & 102 & 65 \\
\hline 4. & Congenital corneal opacity & $35(2.2 \%)$ & 22 & 13 \\
\hline 5. & Abnormalities of the Iris & $33(2.1 \%)$ & 21 & 12 \\
\hline 6. & Heterochromia iridium & $31(1.97 \%)$ & 19 & 12 \\
\hline 7. & Congenital esotropia & $23(1.46 \%)$ & 14 & 9 \\
\hline 8. & Microphthalmos with microcornea & $18(1.14 \%)$ & 11 & 7 \\
\hline 9. & Congenital ptosis & $8(0.5 \%)$ & 6 & 2 \\
\hline 10. & $\begin{array}{l}\text { Minor lid abnormalities (symblepharon, } \\
\text { ankyloblepharon, and epicanthal folds) }\end{array}$ & $9(0.57 \%)$ & 6 & 3 \\
\hline 11. & Congenital ectropion & $5(0.3 \%)$ & 3 & 2 \\
\hline 12. & Anophthalmos & $3(0.2 \%)$ & 2 & 1 \\
\hline
\end{tabular}

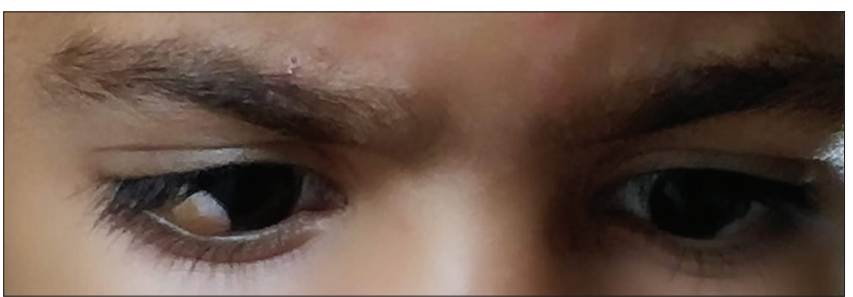

Figure 2: Bilateral limbal dermoid with iridochoroidal coloboma

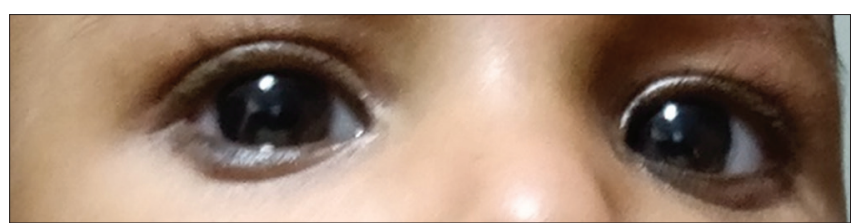

Figure 3: Esotropia

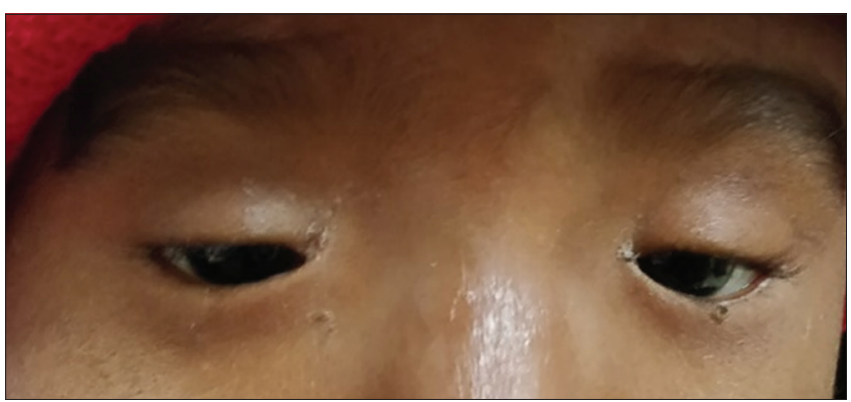

Figure 4: Congenital ptosis (lid) abnormalities

\section{DISCUSSION}

This research was carried out in a tertiary hospital in one of India's most impoverished regions. Muslims make up the majority of the population. All patients are directed to this medical college and hospital since it is the only tertiary care facility within a $100 \mathrm{~km}$ radius. The data represent the real data of the region because it is the only tertiary hospital in the area. There is a low literacy rate, as well as a lack of health knowledge and a significant risk of consanguinity. There is coexistence of maternal malnutrition and infections. All these contribute to high chances of congenital abnormality. Ocular morbidity and death can be greatly decreased if these instances are detected and treated early.

The prevalence of congenital eye anomalies was found to be $0.047 \%$ in our study area. In a study done by Parag and Sagar, the prevalence was reported to be $0.75 \% .{ }^{15}$ In our study, males made up $57.4 \%$ of the patients, while females made up $42.6 \%$. This matches the findings of Behera et al., who found that out of 60 patients, 35 (58.3\%) were male and $25(41.7 \%)$ were female. ${ }^{16}$ Other studies have also revealed a male preponderance. ${ }^{12,15}$ We discovered that $64 \%$ of patients were under the age of 1 year, with $24 \%$ in the age bracket of 1-2 years. This is comparable to another study done in Indian children, where $54 \%$ of the cases were children under the age of 2 years. ${ }^{15}$ It is possible that this is due to the early identification of congenital abnormalities.

Among the ocular anomalies, the most common anomaly in our study was congenital nasolacrimal duct blockage (65\%), followed by coloboma of iris, choroid, and cataract. Other two studies in Indian patients found similar results, with the most common ocular abnormality being dacryocystitis (24\%) and (33.3\%), respectively. ${ }^{15,16}$ Another study showed that microphthalmos, microcornea, and iris coloboma $(67 \%)$ were the most common congenital ocular anomalies, ${ }^{17}$ while in this study, microphthalmos with microcornea was observed in $18(1.14 \%)$ patients. In our study, anophthalmos accounted for $0.2 \%$ of all congenital anomalies. In a study, Bermejo and Martines-Frias reported a $5 \%$ prevalence of anophthalmos. ${ }^{14}$

Eye anomalies are usually difficult to diagnose for the non-specialist. In order to prevent ocular morbidities, pediatricians need to be aware of the importance of these anomalies and report them to ophthalmologist at birth. Greater coordination of these two specialties can prevent many cases of blindness. 
Limitations of the study

This study restricts to the pattern of congenital anomalies; we could not assess the etiological correlation with anomalies.

\section{CONCLUSION}

It is necessary to discover the spectrum of congenital ocular abnormalities as well as the etiological diagnosis of patients to allow efficient prevention and health promotion. The key to preventing childhood blindness is early detection and intervention of the congenital eye anomalies. Non-specialists sometimes have difficulty diagnosing eye abnormalities. For preventing ocular morbidity, it is essential to understand the relevance of these abnormalities. It is also important for the Paediatrician to understand the significance of referring such children to the ophthalmologist at birth. Patient with congenital ocular anomalies and their parents should be informed about their visual prognosis, possible current therapies, and genetic counseling.

\section{ACKNOWLEDGMENT}

The authors acknowledge Department of Pediatrics ad Ophthalmology, SHKM,Nuh for giving there valuable support in undertaking this study.

\section{REFERENCES}

1. Bourne RR, Flaxman SR, Braithwaite T, Cicinelli MV, Das A, Jonas JB, et al. Magnitude, temporal trends, and projections of the global prevalence of blindness and distance and near vision impairment: A systematic review and meta-analysis. Lancet Glob Health. 2017;5(9):e888-e897.

https://doi.org/10.1016/S2214-109X(17)30293-0

2. Levin AV. Congenital eye anomalies. Pediatr Clin North Am. 2003;50(1):55-76.

https://doi.org/10.1016/s0031-3955(02)00113-x

3. Gilbert C, Rahi JS and Quinn GE. Visual impairment and blindness in children. In: Johnson GJ, Minassian D, Weale W and West S, editors. The Epidemiology of Eye Disease. $2^{\text {nd }}$ ed. London: Arnold Publishers; 2003. p. 260-286.

4. Mariotti SP. Global Data on Visual Impairments 2010. Geneva,
Switzerland: World Health Organization; 2012.

5. Gilbert $C$ and Foster A. Childhood blindness in the context of VISION 2020-the right to sight. Bull World Health Organ. 2001;79(3):227-232.

6. Courtright $P$, Hutchinson $A K$ and Lewallen $S$. Visual impairment in children in middle- and lower-income countries. Arch Dis Child. 2011;96(12):1129-1134. https://doi.org/10.1136/archdischild-2011-300093.

7. Gogate $P$, Kalua K, and Courtright P. Blindness in childhood in developing countries: Time for a reassessment? PLoS Med. 2009;6(12):e1000177.

https://doi.org/10.1371/journal.pmed.1000177

8. World Health Organization. Global Initiative for the Elimination of Avoidable Blindness, Who Global Report. Geneva, Switzerland: World Health Organization; 2000.

9. Morrison D, FitzPatrick D, Hanson I, Williamson K, van Heyningen $V$ and Fleck $B$. National study of microphthalmia, anophthalmia, and coloboma (MAC) in Scotland: Investigation of genetic aetiology. J Med Genet. 2002;39(1):16-22. https://doi.org/10.1136/jmg.39.1.16

10. Verma A and FitzPatrick D. Anophthalmia and microphthalmia. Orphanet J Rare Dis. 2007;2:47. https://doi.org/10.1186/1750-1172-2-47

11. Gregory-Evans CY, Williams MJ, Halford S and Gregory-Evans K. Ocular coloboma: A reassessment in the age of molecular neuroscience. J Med Genet. 2004;41(12):881-891. https://doi.org/10.1136/jmg.2004.025494

12. Chuka-Okosa CM, Magulike NO and Onyekonwu GC. Congenital eye anomalies in Enugu, South-Eastern Nigeria. West Afr J Med. 2005;24(2):112-124. https://doi.org/10.4314/wajm.v24i2.28178

13. Lawan A. Congenital eye and adnexial anomalies in Kano, a five-year review. Niger J Med. 2008;17(1):37-39. https://doi.org/10.4314/njm.v17i1.37352

14. Bermejo E and Martines-Frias ML. Congenital eye malformations: Clinical-epidemiological analysis of 1, 124, 654 consecutive births in Spain. Am J Med Genet. 1998;75(5):497-504.

15. Parag NT and Sagar VC. A study on prevalence of congenital ocular anomalies in paediatric age group. Int J Med Res Health Sci. 2015;4(4):884-888. https://doi.org/10.5958/2319-5886.2015.00177.0

16. Behera S, Chowdhury RK and Sar M. A clinico-embryological study of congenital ocular and its adnexal anomalies in a tertiary care hospital. Int J Anat Res. 2019;7(1.2):6138-6143. https://doi.org/10.16965/ijar.2018.422

17. Kumar A, Shukla A and Matoli D. Study of congenital ocular anomalies prevalent in routine eye OPD in a Tertiary Care Hospital. Ophthalmol Res Int J. 2019;11(2):1-7.

https://doi.org/10.9734/or/2019/v11i230122

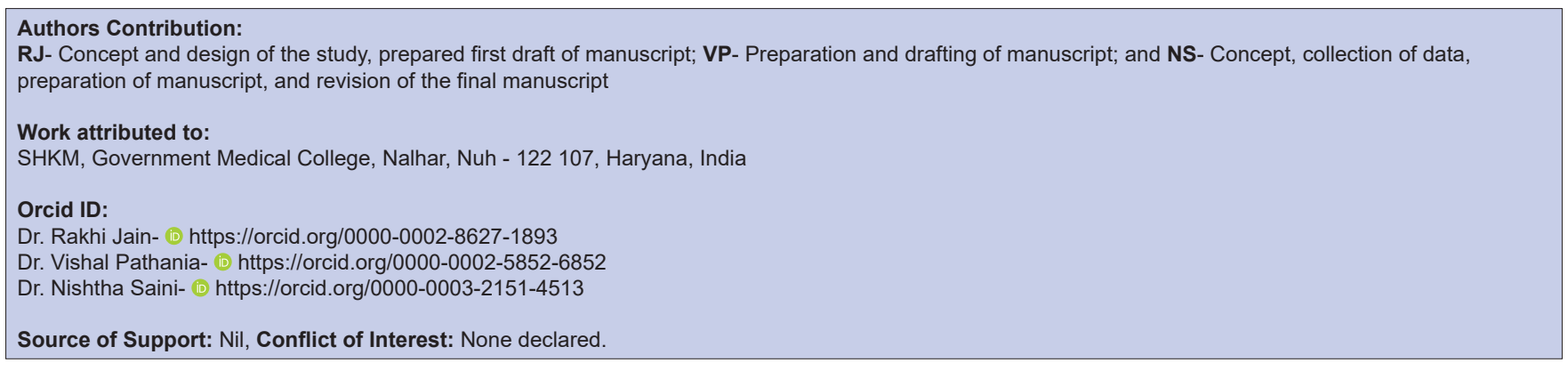

